\title{
Editorial
}

\section{La divulgación científica gerencial}

El haber editado mấs de diez números le da a la Revista Venezolana de Gerencia un status especial en las experiencias editoriales académicas venezolanas. Es este uno de los privilegios en formar parte de su equipo Asesor, y tener la oportunidad de elaborar el Editorial de este número.

Complace igualmente el que la Revista venga del interior del país. En nuestra sociedad, los recursos para el desarrollo académico se distribuyen desiguaimente entre la capital y el resto del país. Además la toma de decisiones en tantos asuntos que nos afectan a todos los pobladores, cualquiera sea sulugar de residencia, están muy influidos por el desenvolvimiento de la capital. Es necesario divulgar una buena calidad de trabajo académico, no importa el lugar del país de donde provenga, pero siempre hay que tener presente romper mitos centralizantes y fortalecer nuevos centros de atracción para el debate y el intercambio.

La Revista no por provenir del interior, orienta su contenido a asuntos provincianos, por el contrario, el presente número dedica una especial atención a asuntos de una marcada universalidad, tales son los casos de las nuevas tecnologías de información y gestión, las comunidades virtuales, los productos informáticos y digitales. Ya que a propósito de las nuevas tecnologias, que incentivan y facilitan las comunicaciones, cada vez tenemos mayores posibilidades de asociar a nuestro trabajo cotidiano a colegas y pares de cualquier lugar del planeta. Asi que podemos intercambiar nuestros puntos de vista, con otros que nos permiten contrastar y con ello reafirmar o revisartesis, métodos, enfoques. Igualmente se nos abren puertas para universalizar nuestros esfuerzos académicos, que trascienden fácilmente las fronteras nacionales.

También es significativo destacar, la vinculación de su contenido con el desenvolvimiento de los Programas de Postgrado. Además, su contenido es la expresión del esfuerzo académico, que se realiza en la Universidad del Zulia, en los temas vinculados con la gestión. Se trata de una consideración muy relevante y necesario que se subraye. Entendiendo que la vinculación Investigación y Postgrado es absolutamente natural y necesaria, por lo que ambos procesos en su propia dinámica se refuerzan, brindando a cada actividad una profundización de sus logros. Las contribuciones que llenan las páginas no sólo de este número, sino de otros anteriores, evidencian la vinculación de los autores de artículos con las lineas de investigación y trabajo de programas de Maestria y de Doctorados.

Con el análisis de los articulos que se han publicado, se deriva una conclusión que importa valorar, como es el espacio reflexivo para los asuntos de la gerencia. ¿Por que destacar el énfasis en lo reflexivo?, Sencillamente porque está muy generalizada la percepción de la gerencia 
como solamente una actividad práctica, o como un arte, en donde las cualidades personales de los gerentes son el eje del todo. Pero se ha soslayado su carácter de acción de los ciudadanos, y su intima vinculación con las instituciones e intereses que ellos representan, asi como las consideraciones contextuales bajo las cuales se desenvuelva la acción gerencial. Hay profundas complejidades detrás de esta afirmación. Por tal razón, cabe valorar la construcción de espacios reflexivos para este ámbito de la acción humana. Entendiendo que la acción reflexiva es la que se entrelaza, con el mantenimiento de una publicación académica, el desarrollo de la investigación y de los programas de postgrado. Se complementa este tripode con una efectiva y real vinculación con los espacios del accionar de la vida de las sociedades, de sus instituciones $y$ de sus actores en las diferentes capas gerenciales y en los estratos humanos de la base productiva, con los que se interactúa, así como con los usuarios y demandantes.

\section{Héctor Lucena *}

* Asesor de la Revista Venezolana de Gerencia. Investigador en el área de Estudios del Trabajo y Protesor Titular de la Universidad de Carabobo (UC) en Venezuela. Autor de varios libros y numerosos artículos publicados en revistas cientificas. Ponente en numerosos eventos científicos, nacionales e intemacionales. Actualmente Coordinador del doctorado en Ciencias Sociales de la UC. E-mail: hlucena@postgrado.uc.edu.ve 